\title{
Familial Hypocalciuric Hypercalcemia in an Index Male: Grey Zones of the Differential Diagnosis From Primary Hyperparathyroidism in a 13-Year Clinical Follow up
}

\author{
Kateřina ZAJÍČKOVÁ ${ }^{1}$, Marcela DVOŘÁKOVÁ ${ }^{1}$, Jitka MORAVCOVÁ ${ }^{1}$, Josef VČELÁK ${ }^{1}$, \\ David GOLTZMAN ${ }^{2}$
}

${ }^{1}$ Institute of Endocrinology, Prague, Czech Republic, ${ }^{2}$ Department of Medicine, McGill University and McGill University Health Centre, Montreal, Canada

Received May 13, 2020

Accepted May 31, 2020

\begin{abstract}
Summary
Familial hypocalciuric hypercalcemia $(\mathrm{FHH})$ type 1 , caused by a heterozygous inactivating mutation of the gene encoding the calcium-sensing receptor (CaSR), is characterized by mild to moderate hypercalcemia, hypocalciuria and inappropriately normal or elevated parathyroid hormone (PTH). FHH must be differentiated from primary hyperparathyroidism (PHPT) because parathyroidectomy is ineffective in the former. Herein, we report a 39-year-old male patient with a 13-year history of asymptomatic PTH-dependent hypercalcemia (mean calcium of $2.88 \mathrm{mmol} / /$; reference range $2.15-2.55 \mathrm{mmol} / \mathrm{l}$ ) and calcium-tocreatinine clearance ratio $(\mathrm{Ca} / \mathrm{Cr})$ ranging from 0.007 to 0.0198 , which is consistent with either FHH or PHPT. Although a family history of hypercalcemia was negative, and PET-CT with fluorocholine was suggestive of a parathyroid adenoma, genetic analysis of the CaSR gene identified a heterozygous inactivating mutation NM_000388.4:c.1670G>A p. (Gly557Glu) in exon 6 and a polymorphism NM_000388.4:C.1192G>A p. (Asp398Asn) in exon 4. The G557E mutation has been previously reported in a Japanese family in which all family members with the mutation had $\mathrm{Ca} / \mathrm{Cr}$ below 0.01 consistent with $\mathrm{FHH}$. The biochemical profile of FHH and PHPT may overlap. Our FHH patient with a G557E CaSR mutation illustrates that the differential diagnosis can be difficult in an index case with no family history, (false) positive parathyroid imaging and higher calciuria than expected for FHH. Calcium intake, vitamin D status and bone resorption might have contributed to the $\mathrm{Ca} / \mathrm{Cr}$ variations over a 13-year clinical follow up. This case thus emphasizes the irreplaceable role of genetic testing of the CaSR gene when clinical evaluation is inconclusive.
\end{abstract}

\section{Key words}

Familial hypocalciuric hypercalcemia • Calcium-sensing receptor • Primary hyperparathyroidism • Calcium-to-creatinine clearance ratio • Bone mineral density

\section{Corresponding author}

K. Zajíčková, Institute of Endocrinology, Národní 8, Prague, Czech Republic. E-mail: kzajickova@endo.cz

\section{Introduction}

Familial hypocalciuric hypercalcemia $(\mathrm{FHH})$ type 1 is caused by a heterozygous inactivating mutation of the gene for the calcium-sensing receptor (CaSR) (Pollak et al. 1993). FHH is a relatively benign disease characterized by mild to moderate hypercalcemia, hypocalciuria and, with respect to hypercalcemia, inappropriately normal or elevated parathyroid hormone (PTH) (Lee and Shoback 2018, Shinall et al. 2013). A family history of hypercalcemia can be helpful because FHH is inherited as an autosomal dominant trait. However, mutations in the CaSR gene may occur de novo in around $15-30 \%$ of cases (Hendy et al. 2000, Pidasheva et al. 2004, Hannan et al. 2016, Lee and Shoback 2018). A negative family history thus does not exclude the disease. Currently, primary hyperparathyroidism (PHPT) is most often identified by routine screening of serum calcium which discloses hypercalcemia, and these patients are generally asymptomatic (Bilezikian et al. 2014). These modern presentations of PHPT are generally associated with only subtle elevations of PTH

PHYSIOLOGICAL RESEARCH • ISSN 1802-9973 (online) 
and often normal urine calcium excretion. Moreover, this milder PHPT can be associated with smaller parathyroid adenoma weight and therefore with false negative parathyroid imaging (Kuzminski et al. 2018). The clinical and biochemical findings of FHH and PHPT may, therefore, significantly overlap. It is important to differentiate these two entities because parathyroid surgery normalizes biochemical abnormalities only in PHPT, and should be avoided in FHH (Bilezikian et al. 2014, Lee and Shoback 2018, Shinall et al. 2013).

Here, we present a 39 -year-old male patient with a biochemical picture of moderate parathyroid-dependent hypercalcemia and normal-to elevated urine calcium excretion which would fit both FHH and PHPT. The case is complicated by the fact that there was no family history of hypercalcemia. We describe diagnostic challenges in distinguishing both diseases.

\section{Methods}

\section{Biochemical analysis}

Fasting blood samples were collected and total serum calcium, phosphorus, serum creatinine, serum albumin, urinary calcium and creatinine were measured photometrically on the Cobas 6000 analyzer (Roche Diagnostics GmbH, Basel, Switzerland) in the Department of Clinical Biochemistry of the Institute of Endocrinology. The albumin-adjusted calcium concentration was calculated as adjusted calcemia $(\mathrm{mmol} / \mathrm{l})=$ total calcemia $(\mathrm{mmol} / \mathrm{l})+0.02 \times(41.3-$ plasma albumin (g/l)) (Barth et al. 1996, Jabor 2008). Serum ionized calcium was determined potentiometrically by an ion-selective electrode on Prime ES Comp analyzer (Nova Biomedical, Waltham, USA). Serum intact PTH ( $2^{\text {nd }}$-generation) concentration and serum osteocalcin concentration were each determined by the Electrochemiluminescence Immunoassay (ECLIA). Serum 25-hydroxyvitamin D (25OHD) and beta-Cterminal telopeptide of type I collagen levels were measured by the ECLIA to determine vitamin D status and bone resorption, respectively.

24-h calcium-to-creatinine clearance ratio $(\mathrm{Ca} / \mathrm{Cr})$ was calculated as previously published (24-h urine calcium x plasma creatinine/plasma calcium x 24-h urine creatinine) (reviewed in Bertocchio et al. 2018 and Lee and Shoback 2018).

A pro-FHH risk equation was also calculated which takes into account serum calcium, PTH, and serum osteocalcin concentrations, and calcium-to-creatinine clearance ratios (Bertocchio et al. 2018, available also at https://maladiesrares-calcium-phosphore.com/pro-fhh-anew-tool-to-predict-primary-hyperparathyroidism/).

\section{Imaging methods}

Bone mineral density (BMD) was assessed by Dual-energy X-ray Absorptiometry (DXA, Lunar Prodigy, Madison, USA) at the lumbar spine (L1-L4), at the hip, at the femoral neck and at the proximal third of the radius.

MIBI scintigraphy and fluorocholine PET-CT were carried out in the University Hospital in Prague and have been described elsewhere (Zajíčková et al. 2018).

\section{Molecular genetic analysis of the CaSR gene}

DNA was isolated from peripheral blood using the Quick Gene DNA whole blood kit L (Kurabo Industries, Osaka, Japan). The sample was analyzed by next generation sequencing (NGS) of PCR products of all coding parts of the CaSR gene (exons 1-7) including $3^{\prime}$ and 5' UTR regions with intron overhangs, extended with promoter sequencing in the range (chr3: 121901568121902283) using a Nextera XT kit (Illumina, San Diego, USA) on an MiSeq (Illumina) sequencer. MiSeq Reporter (Illumina) software was used for data analysis. Bioinformatics procedures and algorithms were used for evaluation against the reference genome GRCh37/hg19 and transcript variant NM_000388.4.

\section{Results}

\section{Case presentation}

Herein, we report a 39-year-old male with a 13-year history of asymptomatic hypercalcemia (mean calcium was $2.88 \mathrm{mmol} / \mathrm{l}$ ). PTH has been oscillating around the upper range of normal with a mean level of $68.5 \mathrm{ng} / 1$ (Table 1). He was first referred to the clinical endocrinology department for evaluation of acne and his hypercalcemia was incidentally identified by routine laboratory assessment at the time he first presented. Initially, in years 2007-2010 we observed asymptomatic moderate hypercalcemia in a young man with a calciumto-creatinine clearance ratio $(\mathrm{Ca} / \mathrm{Cr})$ between 0.008 0.009 , compatible with a diagnosis of FHH. His bone remodeling markers were normal, bone mineral density (BMD) assessed by DXA was higher than average for his age and no lithiasis and/or nephrocalcinosis were documented. His 25OHD level was in the lower part of the normal reference range (Table 1). Genetic testing was not available at that time. Both his father (now deceased) and his mother were found to be normocalcemic and his mother also had normal PTH values. The differential 
diagnosis of FHH from PHPT was complicated by the fact that there were no other family members with documented hypercalcemia in whom evaluations could be performed. Between years 2012-2016 his follow up was interrupted. When he returned in 2017 , his $\mathrm{Ca} / \mathrm{Cr}$ had almost doubled (0.014-0.019), whereas serum calcium remained at a constant and moderately elevated level (Table 1). In 2017 and 2018 his biochemistry was consistent with true PHPT, with frankly increased 24-h urinary calcium excretion (mean $9.5 \mathrm{mmol} / 24 \mathrm{~h}$ ), nonsuppressed PTH and slightly elevated beta-cross laps, a bone resorption marker $(0.803 \mathrm{ng} / \mathrm{ml}$; normal 0.01-0.5). His 25OHD concentrations, however, had also increased (Table 1). A pro-FHH risk equation (Bertocchio et al. 2018) was also calculated, but pro-FHH values were intermediate between FHH and PHPT cut-offs (Table 1). Other hormonal evaluations were normal including prolactin, IGF-1, 24-h urinary free cortisol, TSH, free thyroxine, testosterone, calcitonin and chromogranin $\mathrm{A}$ as multiple endocrine neoplasia syndromes were considered in a young adult with probable PHPT (Thakker et al. 2012). To rule out a parathyroid adenoma, in view of his increasing calciuria and an elevated bone resorption marker, the patient underwent Tc-sestamibi scintigraphy, which was negative; however, a PET-CT with fluorocholine revealed an active focus below the left thyroid lobe (Fig. 1). The neck ultrasound did not disclose any lesion corresponding to an enlarged left lower parathyroid gland. CaSR gene sequencing was finally carried out and identified a heterozygous inactivating missense mutation NM_000388.4:c.1670G $>$ A p.(Gly557Glu) in exon 6 (Table 2). This mutation has previously been reported in a Japanese family. Another missense substitution NM_000388.4:c.1192G $>$ A p.(Asp398Asn) was found in exon 4 which was predicted to be a non-functional polymorphism according to bioinformatics functional modelling (Table 2) and because of its relatively high frequency in the general population (1/1758 in Genome Aggregation Database Exomes, https://gnomad.broadinstitute.org). Although initial bone densitometry in 2007 showed an aboveaverage BMD ( $\mathrm{T}$ score at femoral neck +2.0 ), there was a significant decrease in BMD between years 2009-2017 ( $22 \%$ at the femoral neck, $14 \%$ at total hip and $4.5 \%$ at lumbar spine) (Fig. 2). The documented bone loss corresponded to annual BMD change of $2.75 \%$ at the femoral neck, $1.75 \%$ at the total hip and $0.6 \%$ at the lumbar spine.

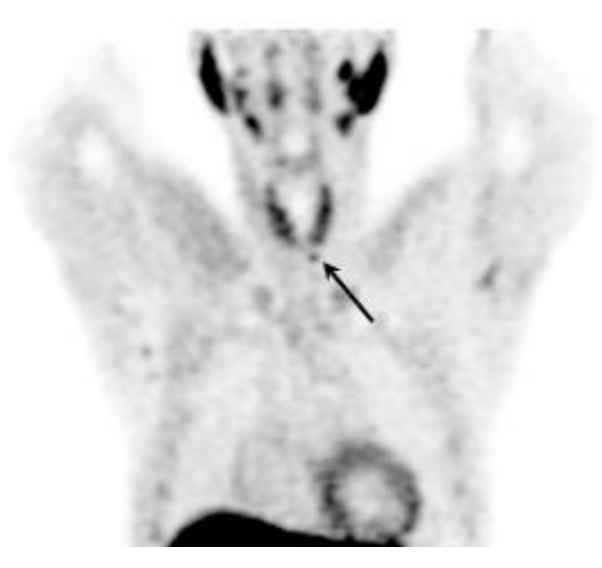

Fig. 1. $18 \mathrm{~F}$-fluorocholine $\mathrm{PET} / \mathrm{CT}$ showing focal hyperactivity dorsal to the left caudal pole of the thyroid gland (arrowheads). Maximal intensity projection.
A.

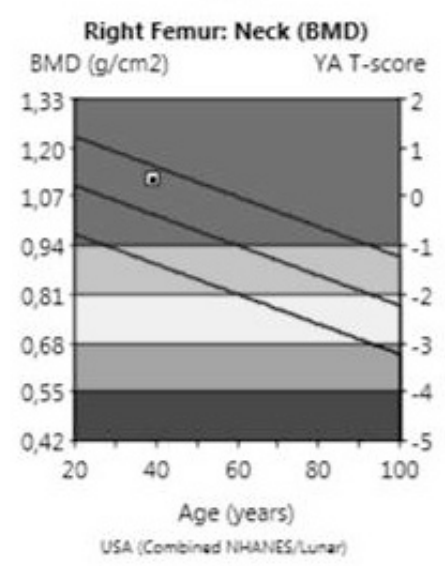

B.

Right Femur: Neck (BMD) \%Change vs Baseline

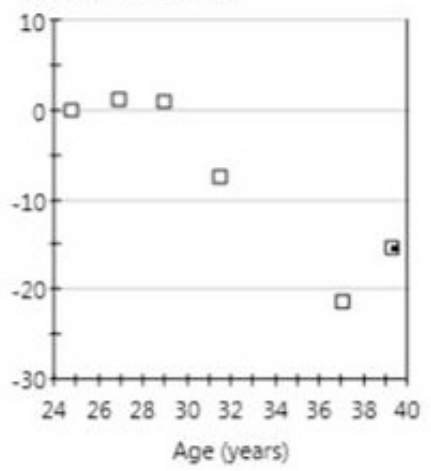

Fig. 2. Bone mineral density (BMD) assessment by Dual-energy X-ray Absorptiometry (DXA) at the right femoral neck in January 2020 (A) and BMD trend between years 2005-2020 (B).

\begin{tabular}{|lccccr|}
\hline \multicolumn{7}{c}{ Densitometry: USA (Combined NHANES/Lunar) } \\
BMD & $\begin{array}{c}\text { YA } \\
(\%)\end{array}$ & $\begin{array}{c}\text { YA } \\
\text { T-score }\end{array}$ & AM & AM \\
Region & $(\mathrm{g} / \mathrm{cm} 2)$ & $(\%)$ & Z-score \\
\hline Neck Right & 1,116 & 104 & 0,4 & 109 & 0,7 \\
\hline
\end{tabular}




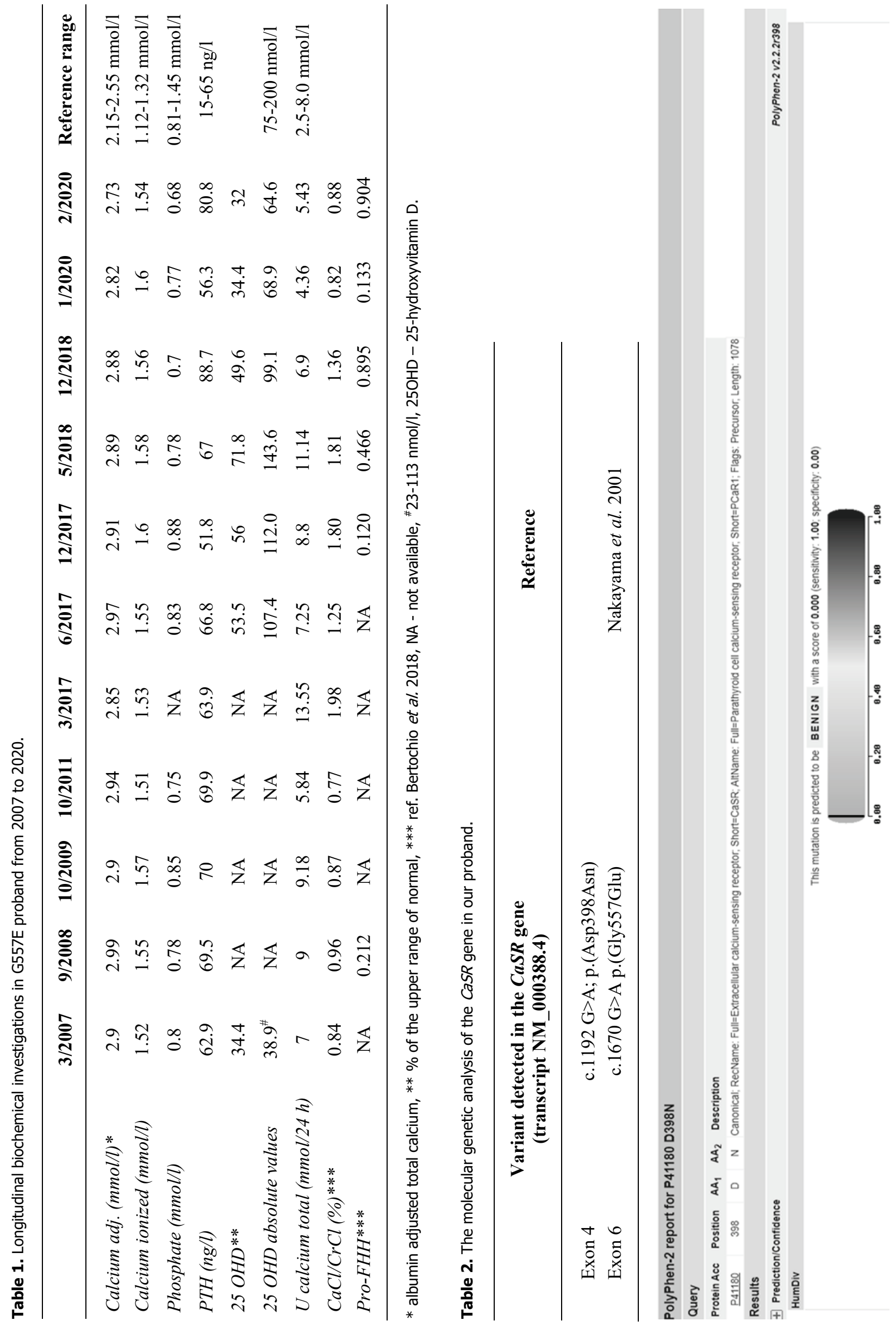




\section{Discussion}

The biochemical profiles of FHH and PHPT overlap considerably. The current FHH patient illustrates that the differential diagnosis can be difficult in an index case with false positive parathyroid imaging and especially higher than expected 24-h urine calcium excretion.

PET-CT with fluorocholine revealed an active focus below the left thyroid lobe suggestive of an enlarged left lower parathyroid gland. In view of our patient's stable serum calcium and parathyroid hormone levels, a true parathyroid adenoma superimposed on $\mathrm{FHH}$ would have been unlikely. Furthermore, although PET-CT with fluorocholine seems to be a highly sensitive and superior parathyroid imaging method, false positivity has been described and linked to the presence of either nodular thyroid disease or enlarged lymph nodes in the cervical and mediastinal regions (Cuderman et al. 2020, Kuzminski et al. 2018, Zajiččková et al. 2018). Furthermore, hyperplasia or tumor multiplicity may occur in the parathyroid glands of FHH individuals (Szabo et al. 2002, Marx 2013). Therefore, the fluorocholine focus could have reflected asymmetrical parathyroid hyperplasia or tumor multiplicity. In such ambiguous clinical settings, genetic testing of the CASR gene seems to be virtually mandatory for establishing the correct diagnosis.

Indeed, genetic testing identified a heterozygous missense mutation in exon 6 that substitutes a glutamic acid for the glycine at codon 557 (G557E). This inactivating mutation has been previously described in a Japanese family where it segregated with hypercalcemia through three generations (Nakayama et al. 2001). Unlike our proband, all family members with the G557E mutation had $\mathrm{Ca} / \mathrm{Cr}$ lower than 0.01 in line with $\mathrm{FHH}$. Nutritional and other factors may play a role in the biochemically disparate phenotypes of the G557E mutation. In the Japanese population calcium intake in general averages $500 \mathrm{mg}$ per day which represents half of the recommended calcium intake in our population (Kobayashi et al. 1997). On the other hand, the level of total serum calcium was comparable to that of our proband with a mean level of $2.8 \mathrm{mmol} / \mathrm{l}$. The functional effect of a G557E mutation has been clearly demonstrated in vitro. After G557E transfection, human embryonic kidney cells had significantly decreased inositol monophosphate signaling after incubation with calcium compared to wild-type, with a calcium set-point that was shifted towards the right (Geng et al. 2016).
G557E is thus a loss-of-function mutation located at the CaSR dimer interaction site which weakens dimer contacts that are necessary for calcium binding to CaSR (Hannan et al. 2016).

Another substitution was found in exon 4, changing aspartic acid to asparagine (D398N). This missense change has not been previously published, but seems not to be pathogenic. Codon 398 is not highly conserved between species (Hendy et al. 2000, Hannan et al. 2016). Furthermore, a relatively high population frequency of D398N has been described in some databases. Several bioinformatics databases have also assigned this mutation as a benign, nonfunctional polymorphism but the results were not completely concordant. Nevertheless, the function of this substitution, especially in the context of a documented mutation, has not been directly tested.

The differential diagnosis between FHH and PHPT is important because parathyroid surgery represents a curative solution with resolution of hypercalcemia only in PHPT. $\mathrm{Ca} / \mathrm{Cr}$ ratio has been recommended by current guidelines as the consensus initial test to differentiate FHH and PHPT with respect to their different handling of renal calcium (Bilezikian et al. 2014). $\mathrm{Ca} / \mathrm{Cr}$ below $1 \%$ was significantly associated with FHH in up to $95 \%$ of patients whereas $\mathrm{Ca} / \mathrm{Cr}$ higher than $2 \%$ was suggestive of PHPT; this leaves a considerable indeterminate range of 1-2\% (Shinall et al. 2013, Lee and Shoback 2018), and milder forms of PHPT are often associated with lower 24-h calcium excretion. A recent paper by Moore et al. (2018) has shown that two-thirds $(62.7 \%)$ of surgically cured patients with mild PHPT had $\mathrm{Ca} / \mathrm{Cr}$ below $2 \%$ and therefore by current recommendations would have been recommended to have pre-operative genetic analysis of the CaSR (Moore et al. 2018). Such findings have weakened the discriminative role of $\mathrm{Ca} / \mathrm{Cr}$ ratio in the differential diagnosis of parathyroid-dependent hypercalcemia.

With the intent of finding a more reliable method to distinguish FHH from PHPT, a pro-FHH risk equation has been developed (Bertocchio et al. 2018). Pro-FHH incorporates $\mathrm{Ca} / \mathrm{Cr}$, plasma calcium, $\mathrm{PTH}$, osteocalcin or bone alkaline phosphatase. This statistical tool was developed to accurately predict whether a patient has PHPT, to reduce the necessity of genetic testing in patients with PTH-related hypercalcemia. However, in our patient with G557E CaSR mutation proFHH values remained in a grey zone between cut-offs for either $\mathrm{FHH}$ or PHPT (Table 1). In contrast, $\mathrm{Ca} / \mathrm{Cr}$ 
calculations, in the 13-year follow-up of our patient, were below $1 \%$ on several occasions, thus raising the suspicion of FHH in a young asymptomatic male with hypercalcemia. Pro-FHH was designed and validated in hypercalcemic cohorts with normal PTH levels. In our patient, intermittently elevated PTH levels, together with higher urine calcium excretion are among the factors which likely contributed to the lack of added value for disease prediction, in comparison with $\mathrm{Ca} / \mathrm{Cr}$. Furthermore, higher bone resorption (although without increased formation markers osteocalcin and alkaline phosphatase) and a decrease in BMD in our patient, could also have influenced pro-FHH calculation.

FHH is believed to be a life-long benign cause of hypercalcemia without any overt complications (Lee and Shoback 2018, Shinall et al. 2013, Žofková 2016). The absence of nephrolithiasis, nephrocalcinosis and/or osteoporosis usually indirectly supports the diagnosis of $\mathrm{FHH}$, although there have been reported FHH cases associated with pancreatitis and chondrocalcinosis (Thakker 2012). Initial bone densitometry in 2007 in our male patient showed normal and even above-average BMD values at the femoral neck. Previous reports have shown that the presence FHH does not lead to low BMD in spite of frequently increased levels of PTH (Abugassa et al. 1992). On the other hand, a few studies have documented an association of $\mathrm{FHH}$ with even higher BMD values than in normal controls (Isaksen et al. 2011, Jakobsen et al. 2014). Mouse models have shown that mutated CaSR attenuated PTH-induced bone resorption (Goltzman and Hendy 2015). Moreover, the issue of whether life-long hypercalcemia in $\mathrm{FHH}$ creates a positive calcium balance across the blood-bone barrier has been considered (Cianferotti et al. 2015). However, in spite of higher BMD on entrance densitometry there was a significant decrease in BMD between years 2009-2017. The highest bone loss occurred at the femoral neck with change of $2.75 \%$ BMD per year. A prospective study has shown that in healthy adult men between 30-40 years of age BMD at the femoral neck declines by only $0.49 \%$ per year (Verroken et al. 2018). The proband in our study did not have any other obvious reasons for accelerated bone resorption. He received no medication and had an appropriate body mass index. During his follow up he was vitamin D sufficient and in laboratory assessment no other endocrinopathy was documented (Vondra et al. 2015). The patient will be carefully followed by DXA in 2-year intervals and the cause of the BMD loss remains to be elucidated.
Accelerated bone loss was one of the factors contributing to higher than expected calciuria in our patient and slightly elevated beta-cross laps, a marker of bone resorption, confirmed the likely contribution of bone resorption. In addition, increased gut absorption of calcium, associated with improved vitamin D status as indicated by increasing $25 \mathrm{OHD}$ concentrations, was likely another factor contributing to $\mathrm{Ca} / \mathrm{Cr}$ variations. Consequently, as a result of increased calcium filtered load, in spite of avid reabsorption by haploinsuficient CaSR in the renal tubular cells, 24-h urinary calcium excretion averaged $9.5 \mathrm{mmol} / \mathrm{day}$ in 2017-2018. This corresponds to frank hypercalciuria in men (defined as calcium excretion more than $7.5 \mathrm{mmol}$ per day) (Bilezikian et al. 2014, Shinall et al. 2013). $\mathrm{Ca} / \mathrm{Cr}$ increased above $1 \%$ and approached almost $2 \%$ (0.014-0.019 in 2017-2018, Table 1). In January 2020 the patient's calciuria decreased and $\mathrm{Ca} / \mathrm{Cr}$ returned below $1 \%$. His biochemical findings thus fluctuated from almost a typical FHH case to an apparent PHPT with $\mathrm{Ca} / \mathrm{Cr}$ being the most variable parameter in his 13-year follow up (0.007-0.0198, coefficient of variation $32 \%$ ). Unlike calciuria, during the follow up, total calcemia and/or ionized blood calcium have remained nearly constant, and PTH fluctuated only slightly around the upper range of normal. The differential diagnosis between FHH and PHPT should therefore not rely on a single $\mathrm{Ca} / \mathrm{Cr}$ measurement because it could provide a false biochemical picture of the disease.

In conclusion, we present an index FHH male patient with an inactivating G557E CaSR mutation which has been previously defined. However, our patient's biochemical phenotype was atypical with calcium excretion being higher than expected for FHH. Calcium intake, vitamin D status and bone resorption might all have contributed to the variation in $\mathrm{Ca} / \mathrm{Cr}$ over a 13 -year clinical follow up and his biochemical findings often resembled true PHPT rather than FHH. Despite its name, his hypercalcemia was neither familial nor hypocalciuric. This case thus emphasizes an irreplaceable role of genetic testing of the CASR gene when clinical settings are ambiguous and inconclusive.

\section{Conflict of Interest}

There is no conflict of interest.

\section{Acknowledgements}

Supported by MZ ČR - RVO (Institute of Endocrinology - EU, 00023761). 


\section{References}

ABUGASSA S, NORDENSTRÖM J, JÄRHULT J: Bone mineral density in patients with familial hypocalciuric hypercalcaemia (FHH). Eur J Surg 158: 397-402, 1992.

BARTH JH, FIDDY JB, PAYNE RB: Adjustment of serum total calcium for albumin concentration: effects of nonlinearity and of regression differences between laboratories. Ann Clin Biochem 33: 55-58, 1996.

BERTOCCHIO JP, TAFFLET M, KOUMAKIS E, MARUANI G, VARGAS-POUSSOU R, SILVE C, NISSEN PH, BARON S, PROT-BERTOYE C, COURBEBAISSE M, SOUBERBIELLE JC, REJNMARK L, CORMIER C, HOUILLIER P: Pro-FHH: a risk equation to facilitate the diagnosis of parathyroid-related hypercalcemia. J Clin Endocrinol Metab 103: 2534-2542, 2018. https://doi.org/10.1210/jc.2017-02773

BILEZIKIAN JP, BRANDI ML, EASTELL R, SILVERBERG SJ, UDELSMAN R, MARCOCCI C, POTTS JT JR: Guidelines for the management of asymptomatic primary hyperparathyroidism: summary statement from the Fourth International Workshop. J Clin Endocrinol Metab 99: 3561-3569, 2014.

CIANFEROTTI L, GOMES AR, FABBRI S, TANINI A, BRANDI ML: The calcium-sensing receptor in bone metabolism: from bench to bedside and back. Osteoporos Int 26: 2055-2071, 2015. https://doi.org/10.1007/s00198-015-3203-1

CUDERMAN A, SENICA K, REP S, HOCEVAR M, KOCJAN T, SEVER MJ, ZALETEL K, LEZAIC L: 18F-fluorocholine PET/CT in primary hyperparathyroidism: superior diagnostic performance to conventional scintigraphic imaging for localization of hyperfunctioning parathyroid glands. J Nucl Med 61: 577-583, 2020. https://doi.org/10.2967/jnumed.119.229914

GENG Y, MOSYAK L, KURINOV I, ZUO H, STURCHLER E, CHENG TC, SUBRAMANYAM P, BROWN AP, BRENNAN SC, MUN HC, BUSH M, CHEN Y, NGUYEN TX, CAO B, CHANG DD, QUICK M, CONIGRAVE AD, COLECRAFT HM, MCDONALD P, FAN QR: Structural mechanism of ligand activation in human calcium-sensing receptor. eLife 19: 1-25, 2016. https://doi.org/10.7554/eLife.13662.032

GOLTZMAN D, HENDY GN: The calcium-sensing receptor in bone--mechanistic and therapeutic insights. Nat Rev Endocrinol 11: 298-307, 2015. https://doi.org/10.1038/nrendo.2015.30

HANNAN FM, BABINSKY VN, THAKKER RV: Disorders of the calcium-sensing receptor and partner proteins: insights into the molecular basis of calcium homeostasis. J Mol Endocrinol 57: R127-R142, 2016. https://doi.org/10.1530/JME-16-0124

HENDY GN, D'SOUZA-LI L, YANG B, CANAFF L, COLE DEC: Mutations of the calcium-sensing receptor (CASR) in familial hypocalciuric hypercalcemia, neonatal severe hyperparathyroidism, and autosomal dominant hypocalcemia. Hum Mutat 16: 281-296, 2000. https://doi.org/10.1002/1098-1004(200010)16:4<281::AIDHUMU1>3.0.CO;2-A

ISAKSEN T, NIELSEN CS, CHRISTENSEN SE, NISSEN PH, HEICKENDORFF L, MOSEKILDE L: Forearm bone mineral density in familial hypocalciuric hypercalcemia and primary hyperparathyroidism: a comparative study. Calcif Tissue Int 89: 285-294, 2011. https://doi.org/10.1007/s00223-011-9517-X

JABOR A: Albumin corrected calcium. (In Czech) In: Vnitřni prostředí. Jabor a kolektiv, Grada, Praha, 2008, p. 74.

JAKOBSEN NF, ROLIGHED L, MOSER E, NISSEN PH, MOSEKILDE L, REJNMARK L: Increased trabecular volumetric bone mass density in familial hypocalciuric hypercalcemia $(\mathrm{FHH})$ type 1: a cross-sectional study. Calcif Tissue Int 95: 141-152, 2014. https://doi.org/10.1007/s00223-014-9877-0

KOBAYASHI M, TANAKA H, TSUZUKI K, TSUYUKI M, IGAKI H, ICHINOSE Y, AYA K, NISHIOKA N, SEINO Y: Two novel missense mutations in calcium-sensing receptor gene associated with neonatal severe hyperparathyroidism. J Clin Endocrinol Metab 82: 2716-2719, 1997. https://doi.org/10.1210/jcem.82.8.4135

KUZMINSKI SJ, SOSA JA, HOANG JK: Update in parathyroid imaging. Magn Reson Imaging Clin N Am 26: 151-166, 2018.

LEE JY, SHOBACK DM: Familial hypocalciuric hypercalcemia and related disorders. Best Pract Res Clin Endocrinol Metab 32: 609-619, 2018. https://doi.org/10.1016/j.beem.2018.05.004

MARX SJ: Multiplicity of hormone-secreting tumors: common themes about cause, expression, and management. J Clin Endocrinol Metab 98: 3139-3148, 2013. https://doi.org/10.1210/jc.2013-1511 
MOORE EC, BERBER E, JIN J, KRISHNAMURTHY V, SHIN J, SIPERSTEIN A: Calcium creatinine clearance ratio is not helpful in differentiating primary hyperparathyroidism from familial herpercalcemic hypocalciuria: a study of 1000 patients. Endocr Pract 24: 1-7, 2018. https://doi.org/10.1177/1078155218796724

NAKAYAMA T, MINATO M, NAKAGAWA M, SOMA M, TOBE H, AOI N, KOSUGE K, SATO M, OZAWA Y, KANMATSUSE K, KOKUBUN S: A novel mutation in Ca2+-sensing receptor gene in familial hypocalciuric hypercalcemia. Endocrine 15: 277-282, 2001. https://doi.org/10.1385/ENDO:15:3:277

PIDASHEVA S, D'SOUZA-LI L, CANAFF L, COLE DEC, HENDY GN: CASR db: calcium-sensing receptor locusspecific database for mutations causing familial (benign) hypocalciuric hypercalcemia, neonatal severe hyperparathyroidism, and autosomal dominant hypocalcemia. Hum Mutat 24: 107-111, 2004. https://doi.org/10.1002/humu.20067

POLLAK MR, BROWN EM, CHOU YH, HEBERT SC, MARX SJ, STEINMANN B, LEVI T, SEIDMAN CE, SEIDMAN JG: Mutations in the human Ca2+-sensing receptor gene cause familial hypocalciuric hypercalcemia and neonatal severe hyperparathyroidism. Cell 75: 1297-1303, 1993. https://doi.org/10.1016/0092-8674(93)90617-Y

SHINALL MC JR, DAHIR KM, BROOME JT: Differentiating familial hypocalciuric hypercalcemia from primary hyperparathyroidism. Endocr Pract 19: 697-702, 2013. https://doi.org/10.4158/EP12284.RA

SZABO E, HELLMAN P, LUNDGREN E, CARLING T, RASTAD J: Parathyroidectomy in familial hypercalcemia with clinical characteristics of primary hyperparathyroidism and familial hypocalciuric hypercalcemia. Surgery 131: 257-263, 2002. https://doi.org/10.1067/msy.2002.120674

THAKKER RV: Calcium-sensing receptor: role in health and disease. Indian J Endocrinol Metab 16: S213-S216, 2012.

THAKKER RV, NEWEY PJ, WALLS GV, BILEZIKIAN J, DRALLE H, EBELING PR, MELMED S, SAKURAI A, TONELLI F, BRANDI ML, ENDOCRINE SOCIETY: Clinical practice guidelines for multiple endocrine neoplasia type 1 (MEN1). J Clin Endocrinol Metab 97: 2990-3011, 2012. https://doi.org/10.1210/jc.2012-1230

VERROKEN C, ZMIERCZAK HG, GOEMAERE S, KAUFMAN JM, LAPAUW B: Bone turnover in young adult men: cross-sectional determinants and associations with prospectively assessed bone loss. J Bone Miner Res 33: 261-268, 2018. https://doi.org/10.1002/jbmr.3303

VONDRA K, STÁRKA L, HAMPL R: Vitamin D and thyroid diseases. Physiol Res 64 (Suppl 2): S95-S100, 2015. https://doi.org/10.33549/physiolres.933083

ZAJIČKOVÁ K, ZOGALA D, KUBINYI J: Parathyroid imaging by (18)F-fluorocholine PET/CT in patients with primary hyperparathyroidism and inconclusive conventional methods: clinico-pathological correlations. Physiol Res 28 (Suppl 3): S551-S557, 2018. https://doi.org/10.33549/physiolres.934029

ŽOFKOVÁ I: Hypercalcemia. Pathophysiological aspects. Physiol Res 65: 1-10, 2016. https://doi.org/10.33549/physiolres.933059 